\title{
INEQUALITIES FOR THE BETA FUNCTION
}

\section{LOÏC GRENIÉ AND GIUSEPPE MOLTENI}

Abstract. Let $g(x):=(e / x)^{x} \Gamma(x+1)$ and $F(x, y):=g(x) g(y) / g(x+y)$. Let $D_{x, y}^{(k)}$ be the $k$ th differential in Taylor's expansion of $\log F(x, y)$. We prove that when $(x, y) \in \mathbb{R}_{+}^{2}$ one has $(-1)^{k-1} D_{x, y}^{(k)}(X, Y)>0$ for every $X, Y \in \mathbb{R}_{+}$, and that when $k$ is even the conclusion holds for every $X, Y \in \mathbb{R}$ with $(X, Y) \neq(0,0)$. This implies that Taylor's polynomials for $\log F$ provide upper and lower bounds for $\log F$ according to the parity of their degree. The formula connecting the Beta function to the Gamma function shows that the bounds for $F$ are actually bounds for Beta.

Mathematics subject classification (2010): Primary 26D07; Secondary 26D99.

Keywords and phrases: Euler Beta function, completely monotone function, explicit bounds.

\section{REFERENCES}

[1] H. Alzer, Some gamma function inequalities, Math. Comp. 60 (1993), no. 201, 337-346.

[2] H. AlZER, On some inequalities for the gamma and psi functions, Math. Comp. 66 (1997), no. 217, 373-389.

[3] H. Alzer, Sharp inequalities for the beta function, Indag. Math. (N.S.) 12 (2001), no. 1, 15-21.

[4] H. Alzer, Some beta-function inequalities, Proc. Roy. Soc. Edinburgh Sect. A 133 (2003), no. 4, 731-745.

[5] H. Alzer, Inequalities for the beta function, Anal. Math. 40 (2014), no. 1, 1-11.

[6] H. Alzer And C. Berg, Some classes of completely monotonic functions, Ann. Acad. Sci. Fenn. Math. 27 (2002), no. 2, 445-460.

[7] H. Alzer And C. Berg, Some classes of completely monotonic functions. II, Ramanujan J. 11 (2006), no. 2, 225-248.

[8] G. E. Andrews, R. Askey, And R. Roy, Special functions, Cambridge University Press, Cambridge, 1999.

[9] K. BALL, Completely monotonic rational functions and Hall's marriage theorem, J. Combin. Theory Ser. B 61 (1994), no. 1, 118-124.

[10] C. BERG, A Pick function related to an inequality for the entropy function, JIPAM. J. Inequal. Pure Appl. Math. 2 (2001), no. 2, Article 26.

[11] C. Berg, J. P. R. Christensen, And P. Ressel, Harmonic analysis on semigroups, Graduate Texts in Mathematics, vol. 100, Springer-Verlag, New York, 1984.

[12] C. Berg AND G. Forst, Potential theory on locally compact abelian groups, Springer-Verlag, New York, 1975.

[13] C. Berg ANd H. L. Pedersen, A completely monotone function related to the gamma function, J. Comput. Appl. Math. 133 (2001), no. 1-2, 219-230.

[14] C. Berg And H. L. Pedersen, Pick functions related to the gamma function, Rocky Mountain J. Math. 32 (2002), no. 2, 507-525, Conference on Special Functions (Tempe, AZ, 2000).

[15] S. Bernstein, Sur les fonctions absolument monotones, Acta Math. 52 (1929), no. 1, 1-66.

[16] L. BONDESSON, Generalized gamma convolutions and related classes of distributions and densities, Lecture Notes in Statistics, vol. 76, Springer-Verlag, New York, 1992.

[17] D. Borwein, J. Borwein, G. Fee, And R. Girgensohn, Refined convexity and special cases of the Blaschke-Santalo inequality, Math. Inequal. Appl. 4 (2001), no. 4, 631-638.

[18] N. BourbaKI, Functions of a real variable, Elements of Mathematics, Springer-Verlag, Berlin, 2004. 
[19] J. Bustoz And M. E. H. Ismail, On gamma function inequalities, Math. Comp. 47 (1986), no. 176, $659-667$.

[20] S. S. Dragomir, R. P. Agarwal, AND N. S. BARnetT, Inequalities for beta and gamma functions via some classical and new integral inequalities, J. Inequal. Appl. 5 (2000), no. 2, 103-165.

[21] W. FELLER, An introduction to probability theory and its applications, Vol. II, Second edition, John Wiley \& Sons Inc., New York, 1971.

[22] A. M. FINK, Kolmogorov-Landau inequalities for monotone functions, J. Math. Anal. Appl. 90 (1982), no. 1, 251-258.

[23] C. L. FRENZEN, Error bounds for a uniform asymptotic expansion of the Legendre function $Q_{n}^{-m}(\cosh z)$, SIAM J. Math. Anal. 21 (1990), no. 2, 523-535.

[24] C. L. FRENZEN, Error bounds via complete monotonicity for a uniform asymptotic expansion of the Legendre function $P_{n}^{-m}(\cosh z)$, Asymptotic and computational analysis (Winnipeg, MB, 1989), Lecture Notes in Pure and Appl. Math., vol. 124, Dekker, New York, 1990, pp. 587-599.

[25] C. L. FRENZEN, Error bounds for the asymptotic expansion of the ratio of two gamma functions with complex argument, SIAM J. Math. Anal. 23 (1992), no. 2, 505-511.

[26] R. L. Graham, D. E. Knuth, and O. Patashnik, Concrete mathematics, second ed., AddisonWesley Publishing Company, Reading, MA, 1994.

[27] F. HaUsdorfF, Summationsmethoden und Momentfolgen, I, Math. Z. 9 (1921), no. 1-2, 74-109.

[28] F. HausdorfF, Summationsmethoden und Momentfolgen, II, Math. Z. 9 (1921), no. 3-4, $280-299$.

[29] F. HAUSdoRfF, Momentprobleme für ein endliches Intervall, Math. Z. 16 (1923), no. 1, $220-248$.

[30] M. E. H. Ismail, L. LorCH, And M. E. Muldoon, Completely monotonic functions associated with the gamma function and its $q$-analogues, J. Math. Anal. Appl. 116 (1986), no. 1, 1-9.

[31] M. E. H. IsmaIL AND M. E. Muldoon, Inequalities and monotonicity properties for gamma and qgamma functions, Approximation and computation (West Lafayette, IN, 1993), Internat. Ser. Numer. Math., vol. 119, Birkhäuser Boston, Boston, MA, 1994, pp. 309-323.

[32] P. IVÁDY, On a beta function inequality, J. Math. Inequal. 6 (2012), no. 3, 333-341.

[33] C. H. Kimberling, A probabilistic interpretation of complete monotonicity, Aequationes Math. 10 (1974), 152-164.

[34] M. MERKLE, Inequalities for residuals of power expansions for the exponential function and completely monotone functions, J. Math. Anal. Appl. 212 (1997), no. 1, 126-134.

[35] C. MoRTICI, An ultimate extremely accurate formula for approximation of the factorial function, Arch. Math. (Basel) 93 (2009), no. 1, 37-45.

[36] M. E. Muldoon, Some monotonicity properties and characterizations of the gamma function, Aequationes Math. 18 (1978), no. 1-2, 54-63.

[37] The PARI Group, Bordeaux, PARI/GP, version 2.6.0, 2013, from http: //pari.math.u-bordeaux.fr/.

[38] H. RobBins, A remark on Stirling's formula, Amer. Math. Monthly 62 (1955), 26-29.

[39] J. B. ROSSER, The complete monotonicity of certain functions derived from completely monotone functions, Duke Math. J. 15 (1948), 313-331.

[40] E. T. Whittaker And G. N. Watson, A course of modern analysis, Fourth edition. Reprinted, Cambridge University Press, New York, 1962.

[41] D. V. Widder, The Laplace Transform, Princeton Mathematical Series, v. 6, Princeton University Press, Princeton, N. J., 1941.

[42] J. WIMP, Sequence transformations and their applications, Mathematics in Science and Engineering, vol. 154, Academic Press Inc., New York, 1981. 